\title{
Three-Year Evaluation of Nosocomial Infection Rates of the ICU
}

\author{
Necla Dereli ${ }^{1}$, Esra Ozayar ${ }^{1}$, Semih Degerli ${ }^{*}$, Saziye Sahin ${ }^{1}$, Filiz Koç ${ }^{2}$
}

1. Anesthesiology and Reanimation Department, Ankara Kecioren Training and Research Hospital, Turkey

2. Infectious Diseases Department, Ankara Kecioren Training and Research Hospital, Turkey

Received from Ankara Kecioren Training and Research Hospital, Turkey.

Submitted on December 30, 2011. Approved on March 20, 2012.

\section{Keywords:}

Cross Infection;

Intensive Care Units;

Outcome Assessment

(Health Care).

\begin{abstract}
Background and objectives: Evaluating the incidence of nosocomial and invasive device-related infections enables the comparison of the health care associated infection (HAl) between the intensive care units of different hospitals and different units in the same hospital.

Material and methods: A retrospective surveillance study was performed to identify nosocomial infections, device-related infections rates, and causal agents from January 2007 through December 2010 in the Anesthesiology Intensive care unit (ICU). HAI were defined according to the CDC (Centers for Disease Control and Prevention) criteria, and invasive device-related infections were defined according to National Nosocomial Infection Surveillance System (NNIS) criteria.

Results: During a two-year period, 939 patients were analyzed throughout a total of 7,892 patientdays. The rates of HAl were $53 \%$ in $2007,29.15 \%$ in $2008,28.85 \%$ in 2009 while $16.62 \%$ in 2010. Most common HAl was blood stream infection. The rate of soft tissue and skin infection was the second most common. Overall, the most common agents were Gram(-) $56.68 \%$, Gram(+) 31.02\% and Candida spp $12.3 \%$ among patients with nosocomial infections.

Conclusions: The incidence of $\mathrm{HAl}$ in the ICU of our hospital was high, compared to the Turkish overall rates obtained at the Refik Saydam Center in 2007. When the rates of device-related infections between 2007 and 2008 were compared, they were higher in 2007. The rates of devicerelated infections were diminished in 2008 to below-national mean rates by infection control measures. Since the rate of urinary catheter-related infections are still high, we should exert continuous efforts for infection control.
\end{abstract}

(c) 2013 Sociedade Brasileira de Anestesiologia. Published by Elsevier Editora Ltda. All rights reserved.
* Corresponding author: Kecioren Kecioren Training and Research Hospital, Department of Anesthesiology Reanimation, Pinarbasi mahallesi Sanatoryum caddesi Ardahan sok. No:25 Kecioren 06380, Ankara, Turkey

E-mail: drsemih@gmail.com

\section{Introduction}

Health care associated infections (HAl) are among the major causes of increased mortality, morbidity, length of stay and cost in the world, as is the case in our country 1-3. Although the number of patients at intensive care units is smaller compared to the number of patients in other clinics, the rate of $\mathrm{HAl}$ is significantly higher in ICU than other units. This is due 
to various invasive therapeutic or diagnostic interventions, such as the use of a wide spectrum of antibiotics, presence of underlying diseases and mechanical ventilation, central venous catheterization, invasive pressure monitoring and urinary catheterization that are frequently used as well for extended periods 4-7. A majority of HAl occurring at intensive care units is associated with invasive device use 4 . The aim of this study was to analyze and evaluate HAl, the sites of these infections, infection rates associated with invasive devices and infection factors at the Anesthesiology intensive care unit of Ankara Keçiören Training and Research Hospital (AKTRH) between the years 2007 and 2010.

\section{Materials and methods}

Anesthesiology intensive care unit of AKTRH is a level III intensive care unit (level 3: must be capable of providing complex, multi-system life support for an indefinite period, and provide mechanical ventilation, extracorporeal renal support services and invasive cardiovascular monitoring for an indefinite period; or care of a similar nature), which has been operational since 2006 . It has nine beds and still serves as a mixed intensive care unit. Nine hundred and thirty-nine patients treated at Anesthesiology intensive care unit between 2007 and 2010 were analyzed in this study.

Patients were accompanied by infection control nurses on a daily basis, and data about patients were collected and analyzed by the infection control physician and attending doctor at the intensive care unit; patients were diagnosed according to National Nosocomial Infection Surveillance System (NNIS) criteria, described below. Blood, urine, tracheal aspirate, perineum, axillary region and nose cultures were taken from patients once a week, the first being on the day of their admission to the intensive care unit. Isolation and characterization of microorganisms were performed by using standard methods at AKTRH Central Microbiology Laboratory. Characterization of $\mathrm{HAl}$ and infections associated with invasive devices (e.g, ventilator, central line, indwelling urinary catheter) were made according to CDC and NNIS criteria, respectively. According to NNIS criteria, the definitions are specific for different sites of infection, onset must occur during hospitalization or shortly after discharge, and the infection may not be present or incubating at the time of the patient's admission. Rates of all nosocomial infections and invasive device associated nosocomial infections were calculated separately for each year. Criteria for specific types of infections are defined as:

- Urinary tract infection (UTI): patients have fever $>38^{\circ} \mathrm{C}$, a positive urine culture, that is $>105$ microorganisms per CC of urine with no more than two species of microorganisms, positive dipstick for leucocyte esterase and / or nitrate, and pyuria;

- Central venous catheter related blood stream infection (CVCRBSI): patient has at least one of the following signs or symptoms: fever $\left(38.8^{\circ} \mathrm{C}\right)$, chills or hypotension; signs, symptoms and positive laboratory results are not related to an infection at another site; common skin contaminant is cultured from two or more blood cultures drawn on separate occasions.

- Ventilator associated pneumonia (VAP): Pneumonia in persons who had a device to assist or control respiration continuously through a tracheostomy or endotracheal intubation within the 48 -hour period before onset of infection, including the weaning period.

Rates of $\mathrm{HAl}$ and invasive device associated infections were calculated according to the formulas given below:
- HAl rate: (HAI number in ICU.1,000-1) / Patient-day

- Urinary catheter related urinary tract infections: (Urinary catheter related urinary tract infections. $1,000^{-1}$ ) / Urinary catheter day

- Central catheter related blood stream infection rate: (Central catheter related blood stream infection. $1,000^{-1}$ ) / central catheter day

- Ventilator associated pneumonia: (Ventilator associated pneumonia. $1,000^{-1}$ ) / ventilator day

\section{Results}

We followed 197 patients for 1637 patient-days in 2007, 209 patients for 2,167 patient-days in 2008, 208 patients for 2005 patient-days in 2009 and 325 patients for 2,083 patient-days in 2010 at the Anesthesiology Intensive Care Unit of Ankara Keçiören Training and Research Hospital. Two hundred and eighty $\mathrm{HAl}$ were detected. HAl rate at our intensive care unit was found to be $53 \%$ in 2007, $29.15 \%$ in $2008,28.85 \%$ in 2009 and $16.62 \%$ in 2010 . Bloodstream infection was the most common type of HAl. This was followed by skin and soft tissue infections. The total of microorganism types isolated at the intensive care unit in a period of four years is shown in Figure 1. The distribution of microorganisms is:

\subsection{0\% Acinetobacter baumanii \\ 19.43\% Candida spp \\ 14.29\% Pseudomonas aeruginosa \\ $13.71 \%$ Coagulase-negative staphylococci \\ 12.57\% Eschericia coli \\ 7.43\% Staphylococcus aureus \\ 6.86\% Klebsiella spp}

Acinetobacter baumanii takes the lead among these factors. Methicillin-Resistant Staphylococcus aureus (MRSA) rate was $61.54 \%$ in staphylococci whereas Extended Spectrum Beta-Lactamase (ESBL) rate in E. coli and Klebsiella spp was found to be $48.72 \%$.

Gram negatives were the most common ones when infection factors were analyzed. The rate of Gram negatives bacteria was $54.86 \%$, Gram positive bacteria was $24.55 \%$ and Candida spp were $19.43 \%$.

After data about the number of patients at intensive care unit, mechanical ventilation day, urinary catheter day, central venous catheter day, number and types of infections were calculated on a monthly basis, surveillance data were obtained for the years 2007-2010. The data obtained were compared to surveillance data of similar intensive care units across the country provided by Refik Saydam Hygiene Center (RSHM) and to that of anesthesiology intensive care units of some hospitals.

Rates of invasive device associated infections were calculated as shown in tables (Tables 1, 2 and 3). Comparison of invasive device associated infection rates at intensive care unit of our hospital with the surveillance data of similar intensive care units in our country provided by RSHM is given in Table 4 and Table 5. 


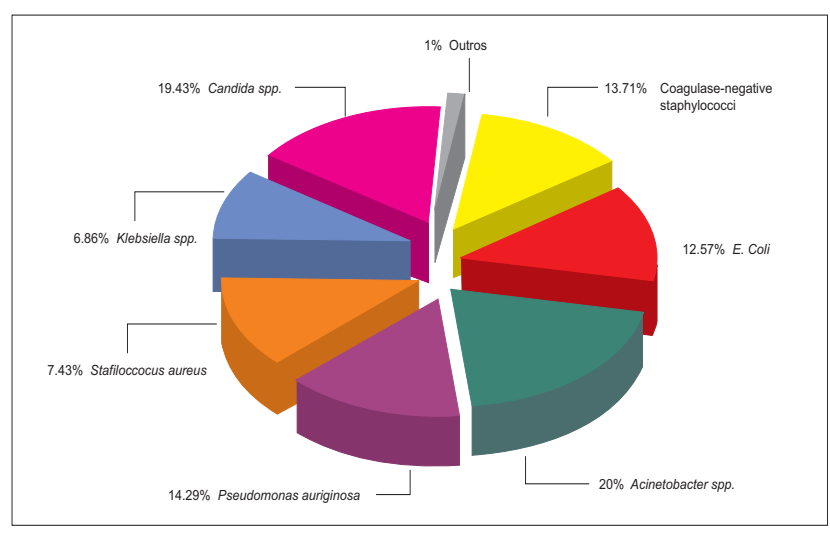

Figure 1 Distribution of Microorganisms.

\section{Discussion}

In the last decade, it has become possible to treat many patients who could have been lost early at intensive care units in the past, thanks to the progress in medical developments and improvement in patient care services. However, higher rates of $\mathrm{HAl}$ in patients at intensive care units result from the presence of several underlying diseases, more frequent and higher number of invasive interventions, use of a wide spectrum of antibiotics and weak immune system due to various reasons. Intensive care units are places with the highest rate of $\mathrm{HAl}$ across the world ${ }^{4-6}$. Although the number of beds in intensive care units constitutes $5-10 \%$ of all beds in hospitals, $25 \%$ of $\mathrm{HAl}$ is seen in these patients. Its prevalence in intensive care units is 5-10 times higher than in other surgery and internal medicine clinics ${ }^{4-9}$.

Table 1 Ventilator Associated Pneumonia Rate in Ankara Keçiören Training and Research Hospital ICU.

\begin{tabular}{lllllll}
\hline AKTRH ICU & $\begin{array}{l}\text { Patient } \\
\text { number }\end{array}$ & $\begin{array}{l}\text { Patient } \\
\text { day }\end{array}$ & $\begin{array}{l}\text { Ventilator } \\
\text { Day }\end{array}$ & VAP & $\begin{array}{l}\text { Rate of } \\
\text { ventilation }\end{array}$ & $\begin{array}{l}\text { VAP } \\
\text { Rate }\end{array}$ \\
\hline 2007 & 197 & 1,637 & 1,469 & 17 & 0.89 & 11.57 \\
2008 & 209 & 2,167 & 1,729 & 4 & 0.80 & 2.31 \\
2009 & 208 & 2,005 & 1,620 & 7 & 0.81 & 4.32 \\
2010 & 325 & 2,083 & 1,444 & 4 & 0.69 & 2.77
\end{tabular}

AKTRH: Ankara Keçiören Training and Research Hospital; ICU: Intensive Control Unit; VAP: Ventilator Associated Pneumonia.

Table 2 Catheter Related Urinary Tract Infection Rate in Ankara Keçiören Training and Research Hospital.

\begin{tabular}{lllllll}
\hline $\begin{array}{l}\text { AKTRH } \\
\text { ICU }\end{array}$ & Patient number & Patient day & $\begin{array}{l}\text { Urinary catheter } \\
\text { day }\end{array}$ & CRUTI & $\begin{array}{l}\text { Rate of urinary } \\
\text { catheter }\end{array}$ & CRUTI rate \\
\hline 2007 & 197 & 1,637 & 1,631 & 20 & 0.99 & 12.26 \\
2008 & 209 & 2,167 & 2,148 & 13 & 0.99 & 6.00 \\
2009 & 208 & 2,005 & 1,975 & 14 & 0.99 & 7.09 \\
2010 & 325 & 2,083 & 2,070 & 9 & 0.99 & 4.35 \\
\hline
\end{tabular}

AKTRH: Ankara Keçiören Training and Research Hospital; CRUTI: Catheter Related Urinary Tract Infection.

Table 3 Central Venous Catheter Related Blood Stream Infection Rate in Ankara Keçiören Training and Research Hospital ICU.

\begin{tabular}{lllllll}
\hline $\begin{array}{l}\text { AKTRH } \\
\text { ICU }\end{array}$ & Patient number & Patient Day & CVC day & CVCR-BSI & Rate of CVC & CVCR-BSI rate \\
\hline 2007 & 197 & 1,637 & 1,556 & 20 & 0.95 & 7.71 \\
2008 & 209 & 2,167 & 1,913 & 3 & 0.88 & 1.57 \\
2009 & 208 & 2,005 & 1,790 & 4 & 0.89 & 2.23 \\
2010 & 325 & 2,083 & 1,632 & 7 & 0.78 & 4.29 \\
\hline
\end{tabular}

AKTRH: Ankara Keçiören Training and Research Hospital; ICU: Intensive Care Unit; CVC: Central Venous Catheter; BSI: Blood Stream Infection. 
Table 4 Incidence Rates - 2007.

\begin{tabular}{llll}
\hline HAI rates & AKTRH & REFIK SAYDAM & \%50 Percentile \\
\hline VAP & 11.57 & $0-39$ & 10.9 \\
CR-UTI & 12.26 & $0-16.8$ & 3.6 \\
CVCR-BSI & 7.71 & $0-21.6$ & 2.7 \\
\hline
\end{tabular}

HAI: Health care associated infections; AKTRH: Ankara Keçiören Training and Research Hospital.

Table 5 Incidence Rates - 2008.

\begin{tabular}{llll}
\hline HAI rates & AKTRH & REFIK SAYDAM & \%50 Percentile \\
\hline VAP & 2.31 & $0-36.9$ & 11.2 \\
CR-UTI & 6.00 & $0-8.8$ & 3.2 \\
CVCR-BSI & 1.57 & $0-14.9$ & 2.4 \\
\hline
\end{tabular}

HAI: Health care associated infections; AKTRH: Ankara Keçiören Training and Research Hospital.

Table 6 Incidence Rates - 2009.

\begin{tabular}{llll}
\hline HAI rates & AKTRH & REFIK SAYDAM & \%50 Percentile \\
\hline VAP & 4.32 & $0-30.8$ & 8.7 \\
CR-UTI & 7.09 & $0-8.8$ & 2.0 \\
CVCR-BSI & 2.23 & $0-13.2$ & 2.2 \\
\hline
\end{tabular}

HAI: Health care associated infections; AKTRH: Ankara Keçiören Training and Research Hospital.

Table 7 Incidence Rates - 2010.

\begin{tabular}{lll}
\hline HAI rates & AKTRH & REFIK SAYDAM \\
\hline VAP & 2.77 & $*$ \\
CR-UTI & 4.35 & $*$ \\
CVCR-BSI & 4.29 & $*$ \\
\hline
\end{tabular}

HAI: Health care associated infections; AKTRH: Ankara Keçiören Training and Research Hospital.

Table 8 Comparison of Invasive Device Related Infection Rates between 2007-2010 years in AKTRH.

\begin{tabular}{lllll}
\hline INFECTION RATES & 2007 & 2008 & 2009 & 2010 \\
\hline VAP & 11.57 & 2.31 & 4.32 & 2.77 \\
CR-UTI & 12.26 & 6.00 & 7.09 & 4.35 \\
CVCR- BSI & 7.71 & 1.57 & 2.23 & 4.29 \\
\hline
\end{tabular}

AKTRH: Ankara Keçiören Training and Research Hospital.

Table 9 ICU Infection Rates in some Universities.

\begin{tabular}{|c|c|c|}
\hline University & Type of ICU & Infection rate $\%$ \\
\hline Atatürk (2000) & Reanimation & 53.3 \\
\hline Bașkent (1999) & Internal medicine/Surgical & 5.3 \\
\hline Çukurova (2000) & Internal medical/surgical & 16.0 \\
\hline Dokuz Eylül (1997) & Internal medicine & 56.1 \\
\hline Erciyes (1999) & Internal medicine/surgical & 25.7 \\
\hline Uludağ (1999) & Reanimation/surgical & 24.0 \\
\hline Akdeniz (2000) & Internal medicine/surgical/Rean. & 19.8 \\
\hline Atatürk (2003) & Reanimation & 29.3 \\
\hline GATA (2001) & Internal medicine/surgical/Rean. & 9.65 \\
\hline
\end{tabular}

GATA: Gülhane Military Medical Academy; Rean.: Reanimation. 
HAl prevalence at intensive care units may vary between hospitals of the same country as well as between countries ${ }^{10,11}$. A study conducted in five different intensive care units in France reported prevalence of HAl to be $26 \%$, whereas it was found to be $22.8-26.1 \%$ in a multi-center study conducted between 1990 and 1997 in Spain. However, this rate was reported to be $20.6 \%$ in European Prevalence of Infection in Intensive Care study ${ }^{12-14}$. In our country, prevalence rates are significantly higher than in other countries ${ }^{15-19}$.

According to studies conducted in some centers in Turkey, HAl rates at intensive care units range from $5.3 \%$ to $56.1 \%$. Different types of intensive care units or difference in surveillance methods may result in such differences. HAl rates in some intensive care units are given in Table $9^{3,20}$. According to surveillance data for similar intensive care units across the country provided by Refik Saydam Hygiene Center, HAI rate is $12.2 \%{ }^{21}$.

HAl rate at our intensive care unit was $53 \%$ in 2007, closer to the upper limit of the country average; it was reduced down to $16.62 \%$ in 2010 to the lower limits of the country average. Since there are many types of intensive care units such as reanimation, internal medicine, mixed and surgery, we deemed it appropriate to compare our results with similar intensive care units, based on a percentile of $50 \%$ and weighted average.

Most of $\mathrm{HAl}$ at intensive care units are invasive device associated infections. There are differences between countries and intensive care units with regards to invasive device associated infections.

VAP is at the top of the list among invasive device associated infections in most of intensive care units. While $47 \%$ of invasive device associated infections were VAP according to an European Prevalence of Infection (EPIC) study conducted at 1,417 intensive care units in 17 western European countries, $41 \%$ of such infections were found to be VAP $(24.1$ per one thousand ventilator days) according to the study conducted by Rosenthall et al. at 55 intensive care units in 8 countries including Turkey ${ }^{22}$.

When the infections in the ICU units of Turkey is analyzed, it is seen that ventilator associated pneumonia incidence was 18.5 per thousand patient-days in 2006, 7.2 in 2007 and 2.3 in 2008 in Hacettepe University Anesthesia Intensive Care Unit. The incidence was calculated to be 19.8 in 2010 in Dicle University Intensive Care Units; 20.92 in Ankara Numune Training and Research Hospital Mixed Intensive Care Unit between the years 2007 and 2010.

According to the nation-wide surveillance data provided by RSHM, ventilator associated pneumonia rate per ventilator days was 10.9 in 2007, 11.2 in 2008 and 8.7 in $2009{ }^{21}$. These are $50 \%$ percentile values and general weighted average is more significant. General weighted average was 17.14 in 2008 and decreased to 15.37 in 2009 . The rate of ventilator associated pneumonia in the anesthesia intensive care unit of our hospital was calculated as 11.57 in 2007, 2.31 in 2008, 4.32 in 2009 and 2.77 in 2010. Our VAP rate was more than the percentile of $50 \%$ in 2007 . It is probable that the rate was high due to our intensive care unit being a newly established unit in 2007: infection control measures were poor, the number of the patients with chronic diseases admitted from chest diseases hospital was high as well as secondary infection rates of mentioned patients. The VAP rate of our hospital decreased below the percentile of $50 \%$ and general weighted average values, as more patients were admitted from our own hospital and ventilator associated pneumonia measures (head elevation to 30-40 degrees, frequent aspiration of subglottic secretions, deep vein thrombosis and peptic ulcer prophylaxis, daily weaning assessment) were reinforced in the following years.

Central venous catheter associated infection rate is $\mathbf{1 2 . 5}$ per thousand central venous catheter days, according to the study by Rosenthall et al. which assesses 55 intensive care units; this rate was calculated as 27.3 in Dicle University intensive care unit in 2010 and 3.75 in Ankara Numune Training and Research Hospital Mixed Intensive Care Unit between 2007 and 2010. According to RSHM country wide data, central venous catheter associated infection rate $50 \%$ percentile values (average) were calculated to be 2.7 in 2007 and 2.4 (weighted average 5.61) in 2008, 2.2 (weighted average 5.01) in $2009{ }^{5}$. Central venous catheter associated infection rate at our hospital was 7.71 in 2007, 1.57 in 2008, 2.23 in 2009 and 4.29 in 2010 . The number was well above the country average in 2007.

We revised our infection control measures. Physicians were dressed in sterile clothing during central venous catheterization. Bigger coverings were used. Daily catheter checks were performed and catheters were taken out as soon as the need was satisfied. Thanks to these measures, 2008 central venous catheter associated infection rate decreased below $50 \%$ percentile values and weighted average. The rate was close to $50 \%$ percentile and below weighted average during 2009. A sharp increase was detected again in 2010. As we cannot access Refik Saydam surveillance data, we cannot make a comparison, however, we revised our infection control measures. According to RSHM country-wide surveillance data, the rate was 3.6 during 2007, 3.2 (weighted average 5.18) during 2008 and 2.0 (weighted average 4.39) during $2009{ }^{21}$. The rate of our intensive care unit was 12.26 during 2007, 6.00 during 2008, 7.09 during 2009 and 4.35 during 2010 . The numbers are above the $50 \%$ percentile and weighted average.

Frequency and distribution of microorganisms that are possible and isolate hospital infections within intensive care units vary according to countries, hospitals and clinics. During the 1970s, gram negative bacilli were common; however, gram positive bacilli increased again due to the use of a wide spectrum of cephalosporins and the increase in invasive interventions. While Gram positive and Gram negative ratios were found to be close in EPIC trial ${ }^{14}$, diverse factors stand out in different centers in Turkey. Gram negative bacteria such as Staphylococcus aureus, Pseudomonas aeruginosa and Acinetobacter baumannii - draw attention in recent studies. The most commonly isolated agents in hospital infections in diverse intensive care units of Turkey are as follows; Staphylococcus aureus (34\%) in Gülhane Military Medical Academy intensive care unit during 2001, Acinetobacter spp (28.4\%) in Osmangazi University Anesthesia intensive care unit during 2003, Pseudomonas spp (27.8\%) between 2005-2009 in Cumhuriyet University Faculty of Medicine 
Reanimation Unit and Acinetobacter baumannii (23.2\%) in Yüzüncü Yıl University Faculty of Medicine intensive care unit during $2009^{3,15,23,24}$.

Our study revealed that $54.86 \%$ of the hospital infections in the intensive care unit is Gram negative while $24.55 \%$ is Gram positive and 19.43 is Candida spp. The most frequently isolated agent is Acinetobacter baumannii. Candida spp follows Acinetobacter baumannii. Ankara Keçiören Training and Research Hospital Anesthesia intensive care unit started its operations as a nine bed unit in 2006 and still functions as both anesthesia intensive care unit and surgical intensive care unit. Thus, our patient range is wide and some of the patients are admitted from chest disease centers nearby. These are the patients who are admitted and discharged frequently and who have long hospitalization periods. Therefore, we often encounter Gram negative microorganisms such as Pseudomonas aeruginosa, Acinetobacter baumanii and Escherichia coli in our intensive care unit. The rest of the patients are easily colonized because of the patients admitted to the intensive care unit due to pulmonary infections. Invasive device associated infection rates were detected to be higher than the rates of the other similar intensive care units during 2007.

Thus, measures were applied in line with the decisions of the infection control committee. Intensive care unit staff was trained regularly and frequently. The staff was trained on hand hygiene, and they were encouraged to acquire hand washing habit. Invasive interventions were performed by experienced physicians dressed in sterile clothing during the interventions. Bigger coverings were used for interventions. Mask and gown use was increased. Invasive devices were taken out as soon as the need was satisfied.

The hospital infection rate, which was 53 during 2007, went down to 16.62 in 2010 , thanks to all these abovementioned measures. Ventilator associated infection rates and central venous catheter associated blood stream infection rates improved when compared to 2007. However, we have not yet achieved the desired level for urinary catheter associated infection rates. When we assess the reasons for high rates we understand that frequent change of staff, failures in infection control measures and material shortcomings are there to blame. In this study we compared hospital infection rates to hospital average rates in the country, demonstrating that our infection control is not worse than average. We believe that persistence in staff training, and applying these to clinical practice are crucial for infection control.

\section{References}

1. Garner JS, Jarvis WR, Emori TG et al. - CDC definitions for nosocomial infections. Am J Infect Control, 1988;16:128-140.

2. Edmond MB, Wenzel RP - The impact of hospital acquired blood stream infections. Emerg Infect Dis J, 2001;7:174-177.

3. Valbona N, Kılıç A, Küçükarslan A et al. - Management of nosocomial infections in intensive care units of a tertiary military hospital. Gülhane Tıp Dergisi, 2004;46:305-310.

4. Akalın $\mathrm{H}$ - Infections in intensive care units: risk factors and epidemiology. Turk J Hosp Infect, 2001;5:5-16.

5. Eggiman P, Pillet D - Infection control in the ICU. Chest Journal, 2001;120:2059-2093.
6. Özsüt $\mathrm{H}$ - The infection problem in intensive care units: resistant microorganisms and antibiotherapy. Hastane Enfeksiyonları Dergisi, 1998;2:5-14.

7. Çağatay Atahan $\mathrm{A}$, Özsüt $\mathrm{H}$ - Infections and antimicrobial therapy in intensive care unit. Yoğun Bakım Dergisi, 2001;1:21-32.

8. Akın A, Çoruh EA, Alp E et al. - The evaluation of nosocomial infections and antibiotic resistance in anesthesia intensive care unit for five years. Erciyes Tip Dergisi, 2011;33:7-16.

9. Weber DJ, Raasch R, Rutala WA - Nosocomial infections in the ICU: the growing importance of antibiotic-resistant pathogens. Chest, 1999; 115:34S-41S.

10. Namıduru M, Karaoğlan I, Göksu S et al. - Causative bacteria in nosocomial infections in surgical intensive care unit and their resistance to antibiotics. Turk J Infect, 2003;17:39-44.

11. Archibald L, Phillips L, Monnet D et al. - Antimicrobial resistance in isolates from inpatients in the United States: increasing importance of the intensive care unit. Clin Infect Dis, 1997;24:211-215.

12. Legras A, Malvy D, Quinioux Al et al. - Nosocomial infections: prospective survey of incidence in five French intensive care units. Intensive Care Med, 1998;24:1040-1046.

13. Vaque J, Rossello J, Arribas JL - Prevalence of nosocomial infections in Spain: EPINE Study 1990-1997. EPINE Working Group. J Hosp Infect; 1999;43:105-111.

14. Vincent JL, Bihari DJ, Suter PM et al. - The prevalence of nosocomial infection in intensive care units in Europe: results of the European Prevalence of Infection in Intensive Care (EPIC) Study. JAMA, 1995;274:639-644.

15. Engin A, Gürelik B, Elaldı N et al. - Nosocomial infections in reanimation intensive care unit of Faculty of Medicine in Cumhuriyet University: a four years suirvelliance study. Yoğun Bakım Dergisi, 2006;6:227-232.

16. Palabıyıkoğlu I, Tulunay $M$, Ünal $N$ et al. - Nosocomial infections observed in a reanimation unit: risc factors, causative agents and antimicrobial resistance. Hastane Enfeksiyonları Dergisi, 2000;4:150-153.

17. Çelik I, İnci N, Denk A et al. - Prevalence of hospital acquired infections in anesthesiology intensive care unit. Firat Tıp Dergisi, 2005;10:132-145.

18. Hadimioğlu N, Gültekin M, Tuncer D et al. - Infections observed in a reanimation unit. İnfeksiyon Dergisi, 1998;12:329-332.

19. Yosunkaya A, Tuncer S et al. - Nosocomial infections in our reanimation unit between years 1999-2000. Hastane İnfeksiyonları Dergisi, 2002;6:92-97.

20. Kadanalı A, Özkurt Z, Erol S et al. - Hospital infections in Atatürk University Medical Faculty Research Hospitals in 2003. Ankem Dergisi, 2004;18:149-152.

21. Surveillance data of Turkey between 2007 and 2010. Refik Saydam National Public Health Agency. 2011; pp. 51-78.

22. Rosenthall VD, Maki DG, Salomao R et al. - Device associated nosocomial infections in 55 intensive care units of 8 developing countries. Ann Intern Med, 2006;145:582-591.

23. Kiremitçi A, Durmaz G, Akgün $Y$ et al. - Frequency of isolation and antimicrobial resistance patterns of the microorganisms isolated from various clinical specimens in an anaesthesia intensive care unit, data of year 2003. İnfeksiyon Dergisi, 2006;20:37-40.

24. Karahocagil MK, Yaman G, Göktaș U et al. - Hastane Enfeksiyon Etkenlerinin ve Direnç Profillerinin Belirlenmesi. Van Tıp Dergisi, 2011;18:27-32. 